\title{
Optimization of process conditions for catalytic alkylation of isomeric cresols with cyclohexene
}

\author{
Mohammad Kamruzzaman, Ashequl Alam Rana and Manoranjan Saha
}

\author{
Department of Applied Chemistry and Chemical Engineering, University of Dhaka, Dhaka-1000, Bangladesh.
}

\begin{abstract}
Alkylation of isomeric cresols with cyclohexene in presence of perchloric acid as catalyst was studied and cyclohexyl cresols obtained in high yield. The effects of the variation of reaction parameters such as temperature, molar ratio of cresol to cyclohexene, amount of perchloric acid and time of reaction were investigated. The yield of the products increased with the increase of each of the above-mentioned parameters. Optimum yield (97.6\% for cyclohexyl $m$-cresol; 95.4\% for 2-cyclohexyl-4-methylphenol and $91.2 \%$ for cyclohexyl $o$-cresol) of the products were obtained under the reaction conditions of a temperature of $140^{\circ} \mathrm{C}$; an $8-6: 1$ molar ratio of cresol to cyclohexene, a $5 \%$ by weight perchloric acid of cresol, a $2 \mathrm{~h}$ time of addition of cyclohexene and a $2 \mathrm{~h}$ time of stirring of the reaction mixture. Considering the yields of cyclohexyl cresols and ease of purifications, the above mentioned conditions were accounted as optimum for the alkylation of isomeric cresols with cyclohexene in the presence of perchloric acid.
\end{abstract}

Keywords: Alkylation, Cyclohexene, Isomeric cresols, Process optimization.

\section{Introduction}

The alkylation of aromatic substrates is important in many sectors of the chemical industry. Alkylation of cresols has earned much interest of the scientists since alkylated cresols may be used as raw materials for the production of resins, durable surface coatings, varnishes, printing inks, surface active agents, antioxidants, fungicides, petroleum additives, and multifunctional stabilizers for fuels, lubricating oils and polymeric materials (Krishnan et al., 2002; Lebedev, 1984; Ravikovich, 1984; Sakthivel et al., 2000; Sato et al., 2001; Subramanian et al., 1997; Zhang et al., 2001). Catalytic alkylations of isomeric cresols with different alcohols and esters have been studied by several research groups (Basak et al., 2004; Devassy et al., 2004; Grabowska et al., 2004; Grabowska and Wrzyszcz, 2001; Saha et al., 2001; Saha and Roy, 1992; Shanmugapriya et al., 2006; Velu and Sivasankar, 1998; Yadav et al., 1999; Yadav and Pathre, 2006). Reports are also available on the alkylation of isomeric cresols with olefins and styrene in presence of different catalysts (Chaudhuri et al., 1990; Kozlikovskii et al., 1986; Sadykhov et al., 1996; Saha et al., 1997; Trocsanyi, 1975; Yadav and Pala, 2000). While alkylation of cresols with alkenes especially cyclohexene was not studied so much. With the best of our knowledge only alkylation of $o-, m$-, and $p$ - cresols with cyclohexene in the presence of aluminum cresolates have been studied (Kozlikovskii, 1887), but no - attempt has so far been made to investigate the reaction of isomeric cresols with cyclohexene in the presence of perchloric acid. Perchloric acid is a protic acid catalyst of industrial importance due to the fact that it is stronger in its action, comparatively less corrosive, and causes no undesirable side reaction.

Process optimization is the discipline of adjusting a manufacturing process so as to optimize some specified set of parameters without violating some constraint. The most common goals are minimizing cost, maximizing throughput, and/or efficiency.

The optimization of chemical processes is a major activity in both process development and library production groups within the chemical industry. Chemistry process optimization requires an understanding of which variables are important to the outcome (yield, purity, cost, etc.) and to what level the variables should be set. As in most scientific disciplines, chemists have historically followed the practice of changing one variable at a time (OVAT) during optimization. Each variable is scanned this way, and the combination of their optimum values is accepted as the global optimum. 
In the present work, the reaction of ortho-, meta- and paracresols with cyclohexene in the presence of perchloric acid as catalyst has been investigated and the yield of cyclohexyl cresols optimized using a set of input variables that included reactant parameters (amount of catalyst and molar ratio of cresol to cyclohexene) and processing variables (temperature, and reaction time).

\section{Materials and Methods}

Chemicals used in this work were purchased from Merck Chemicals Co. and were used without further purification unless stated. Perchloric acid was used as catalyst.

The reactions were carried out in a three necked round bottomed flask fitted with a condenser, a thermometer, a dropping funnel and a stirrer. Cresol-catalyst mixture was charged into the flask, heated to the temperature of the experiment, the cyclohexene was introduced into the mixture gradually over a certain period of time (time of addition) with constant stirring. The reaction mixture was stirred for another period of time (time of stirring) at the same temperature after the addition of the total amount of cyclohexene. The reaction mass was then cooled to room temperature and neutralized with an equivalent amount of $10 \% \mathrm{KOH}$ solution. The neutralized reaction mass was then dissolved in diethyl ether, washed with distilled water several times and dried with anhydrous magnesium sulfate. Unreacted reactants and solvent were distilled off at atmospheric pressure. The product thus obtained was subjected to fractionation by distillation and characterized by physico-chemical and spectral means.

\section{Results and Discussion}

\section{Alkylation of $\boldsymbol{m}$-cresol}

Reaction of m-cresol with cyclohexene was investigated in the presence of perchloric acid over the temperature range of 60 to $140^{\circ} \mathrm{C}$. The reaction gave cyclohexyl $m$-cresol (cyclohexyl group substituted the aromatic ring to the ortho- or para- position with respect to the -OH group). The effect of the variation of temperature, molar ratio of $m$-cresol to cyclohexene, amount of perchloric acid and time of reaction have been shown in Figs. 1-4.

Fig. 1 shows that the yield of the product increased with the rise in temperature. Thus the yield increased from 67.8 to $94.5 \%$ when the temperature was raised from 60 to $140^{\circ} \mathrm{C}$.

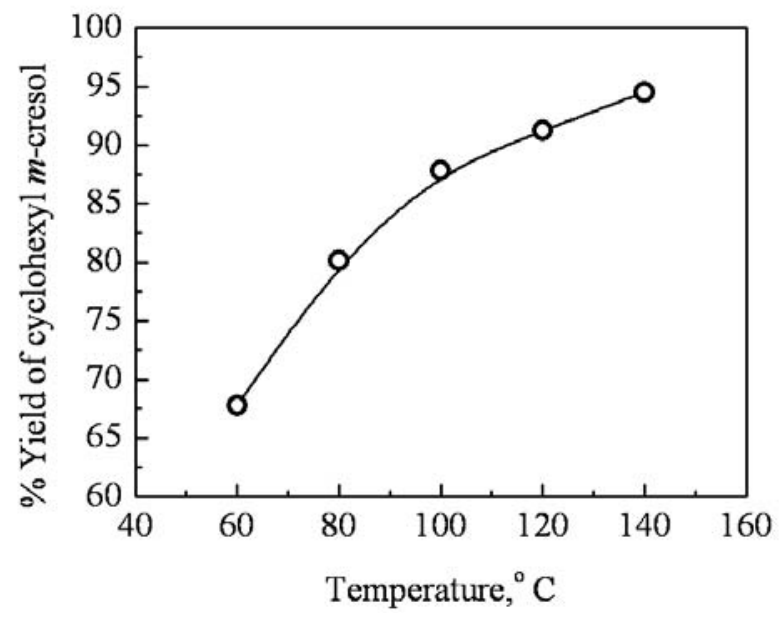

Fig. 1: The effect of variation of temperature on the reaction of $m$-cresol with cyclohexene in the presence of perchloric acid (molar ratio of $m$ cresol to cyclohexene $=8: 1$, amount of catalyst $=$ $5 \%$ by wt. of $m$-cresol, time of addition $=2 \mathrm{~h}$ and time of stirring $=1 \mathrm{~h}$ )

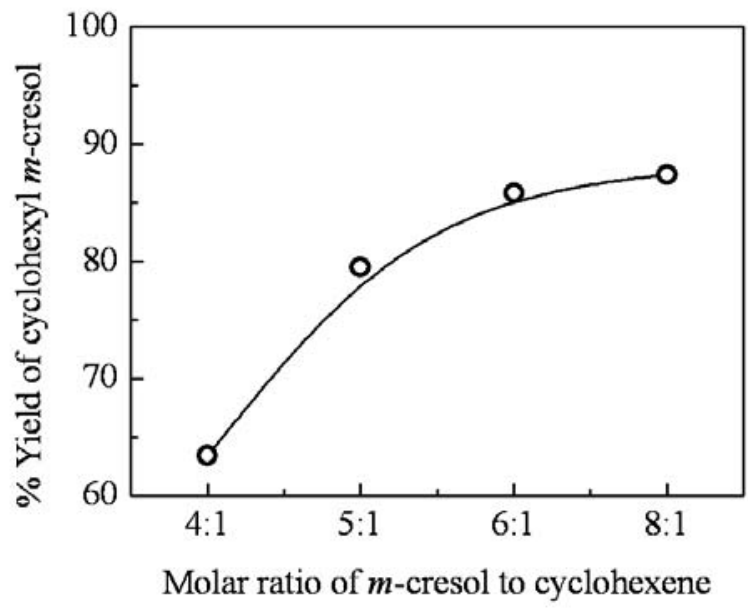

Fig. 2: The effect of variation of molar ratio of $m$-cresol to cyclohexene on the reaction of $m$-cresol with cyclohexene in the presence of perchloric acid (temperature $=140^{\circ} \mathrm{C}$, amount of catalyst $=5 \%$ by wt. of $m$-cresol, time of addition $=2 \mathrm{~h}$ and time of stirring $=1 \mathrm{~h}$ ).

The yield of the product also depended on the molar ratio of $m$-cresol to cyclohexene (Fig. 2). The yield of cyclohexyl mcresol increased from 63.4 to $87.4 \%$ on increasing the molar ratio of $m$-cresol to cyclohexene from 4:1 to $8: 1$.

The effect of the variation of the amount of perchloric acid showed that the yield of the product increased with the 
increase of the amount of catalyst (Fig. 3). By changing the amount of catalyst from 1 to $5 \%$ by wt. of m-cresol, the yield of the product raised from 78.4 to $94.5 \%$. The best yield was obtained when the amount of catalyst was taken in an amount of $5 \%$ by wt. of $m$-cresol.

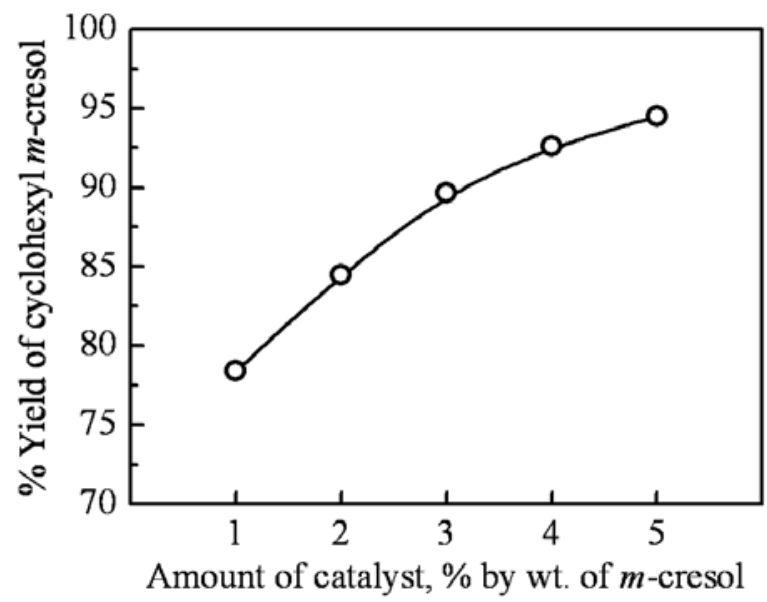

Fig. 3: The effect of variation of the amount of perchloric acid on the reaction of $m$-cresol with cyclohexene (temperature $=140^{\circ} \mathrm{C}$, molar ratio of $m$ cresol to cyclohexene $=8: 1$, time of addition $=2$ $\mathrm{h}$ and time of stirring $=1 \mathrm{~h}$ ).

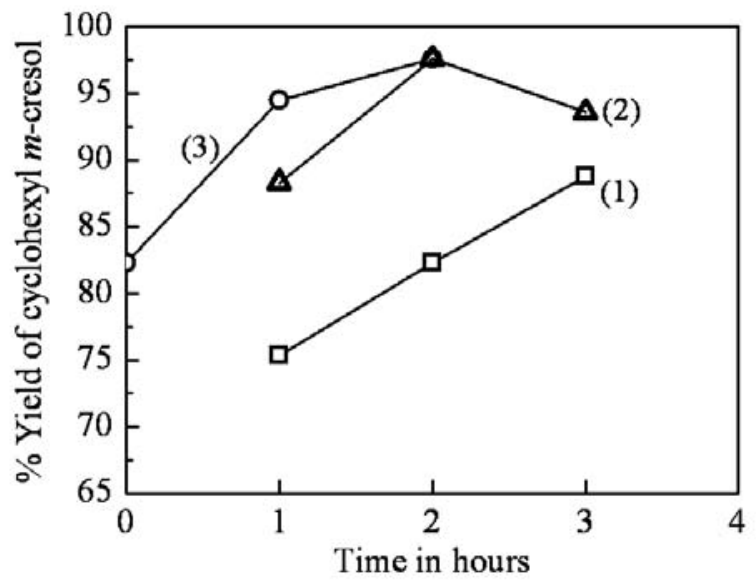

Fig. 4: The effect of variation of reaction time on the yield of cyclohexyl $m$-cresol (temperature $=$ $140^{\circ} \mathrm{C}$, molar ratio of $m$-cresol to cyclohexene $=$ $8: 1$ and amount of catalyst $=5 \%$ by wt. of $m$ cresol): 1- The effect of variation of time of addition (time of stirring = $0 \mathrm{~h}$ ); 2- The effect of variation of time of addition (total time of reaction $=$ $4 \mathrm{~h}$ ) and 3- The effect of variation of time of stirring (time of addition $=2 \mathrm{~h}$ )
Fig. 4 shows the effect of the variation of time of reaction on the yield of the product. The yield of the product increased with the increase of time of addition (Fig. 4, curve 1). By increasing the time of addition to a value greater than $2 \mathrm{~h}$, no significant effect on the yield was observed (Fig. 4, curve 2). The yield also increased by additional stirring (Fig. 4, curve 3 ). The best yield was obtained when the time of stirring was $2 \mathrm{~h}$.

Therefore, the following conditions may be considered as optimum (yield $=97.6 \%$ ) for the production of cyclohexyl $\mathrm{m}$-cresol: temperature $=140^{\circ} \mathrm{C}$, molar ratio of $m$-cresol to cyclohexene $=8: 1$, amount of perchloric acid $=5 \%$ by wt. of $m$-cresol, time of addition $=2 \mathrm{~h}$ and time of stirring $=2 \mathrm{~h}$.

The UV spectrum of cyclohexyl m-cresol in $0.01 \mathrm{M}$ petroleum ether solution showed a strong absorption at $\lambda_{\max }$. $287.5 \mathrm{~nm}$.

The IR spectrum of cyclohexyl $m$-cresol (Fig. 5) showed the absorption bands at $2850-2920 \mathrm{~cm}^{-1}$ for saturated C-H group while band at $775 \mathrm{~cm}^{-1}$ accounted for 1,2,3-trisubstituted benzene ring. Bands near $810 \mathrm{~cm}^{-1}$ and $855 \mathrm{~cm}^{-1}$ indicated the presence of 1,2,4-trisubstituted benzene ring and bands at $1570 \mathrm{~cm}^{-1}$ and $3400 \mathrm{~cm}^{-1}$ were due to aromatic ring and -OH group respectively.

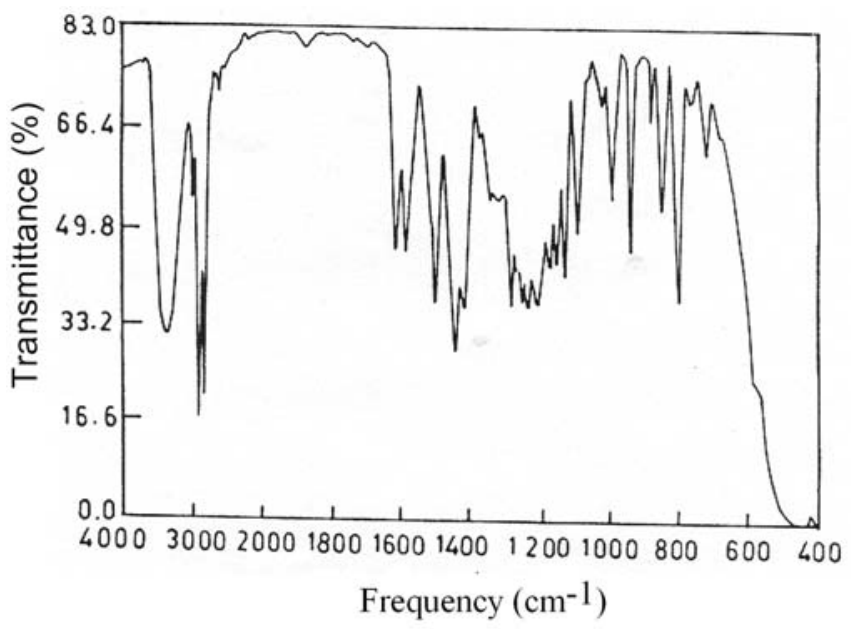

Fig. 5: IR-spectrum of cyclohexyl $m$-cresol

The ${ }^{1} \mathrm{H}$ NMR-spectrum of cyclohexyl $m$-cresol (Fig. 6) showed signal at $\delta=6.13-7.17 \mathrm{ppm}$ for aromatic ring protons. Signals for -OH group proton, methyl group protons, all the protons on the cyclohexane ring except one on the $\alpha$ position relative to the aromatic ring and one proton on the 
$\alpha$-position were observed at $\delta=5.0-5.85 \mathrm{ppm}, \delta=2.03-2.46$ ppm, $\delta=0.77-2.03 \mathrm{ppm}$ and $\delta=2.46-3.17$ respectively.

Cyclohexyl $m$-cresol had b.p. $=310^{\circ} \mathrm{C}, \mathrm{d}_{4}{ }^{20}=0.9971$ and $\mathrm{n}_{\mathrm{D}}{ }^{20}=1.5248$.

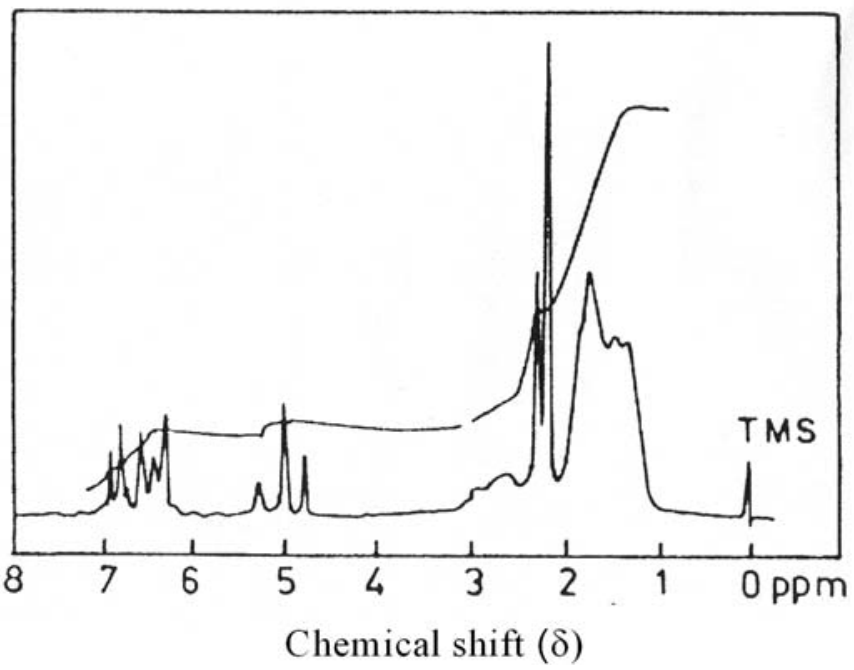

Fig. 6: ${ }^{1} \mathrm{H}$ NMR-spectrum of cyclohexyl $m$-cresol

\section{Alkylation of $p$-cresol}

The results of the reaction of $p$-cresol with cyclohexene in the presence of perchloric acid are presented in the Tables IIV. The reaction gave 2-cyclohexyl-4-methylphenol. The effects of the variation of temperature, molar ratio of $p$ cresol to cyclohexene, amount of perchloric acid and time of reaction on the yield of the product were investigated.

Like cyclohexyl $m$-cresol, the yield of 2-cyclohexyl-4methylphenol increased with the increase of temperature (Table I). The yield increased from 51.3 to $74.3 \%$ on increasing the temperature from 60 to $140^{\circ} \mathrm{C}$.

Table I: The effect of the variation of temperature on the reaction of $p$-cresol with cyclohexene in the presence of perchloric acid (molar ratio of $p$ cresol to cyclohexene $=4: 1$, amount of catalyst $=5 \%$ by wt. of $p$-cresol, time of addition $=2 \mathrm{~h}$ and time of stirring $=1 \mathrm{~h}$ )

\begin{tabular}{lc}
\hline Temp., ${ }^{\circ} \mathrm{C}$ & $\begin{array}{c}\text { \% Yield of 2-cyclohexyl- } \\
\text { 4-methylphenol }\end{array}$ \\
\hline 60 & 51.3 \\
80 & 58.6 \\
100 & 61.2 \\
120 & 68.8 \\
140 & 74.3 \\
\hline
\end{tabular}

Table II: The effect of the variation of molar ratio of $p$ cresol to cyclohexene on the reaction of $p$-cresol with cyclohexene in the presence of perchloric acid (temperature $=140^{\circ} \mathrm{C}$, amount of catalyst $=5 \%$ by wt. of $p$-cresol, time of addition $=2 \mathrm{~h}$ and time of stirring $=1 \mathrm{~h}$ )

\begin{tabular}{lc}
\hline $\begin{array}{l}\text { Molar ratio of } p \text {-cresol to } \\
\text { cyclohexene }\end{array}$ & $\begin{array}{c}\text { \% Yield of 2-cyclohexyl- } \\
\text { 4-methylphenol }\end{array}$ \\
\hline $4: 1$ & 74.3 \\
$5: 1$ & 81.2 \\
$6: 1$ & 86.8 \\
$8: 1$ & 93.6 \\
\hline
\end{tabular}

The yield of the product also increased with the increase of the molar ratio of $p$-cresol to cyclohexene (Table II). The yield of the product increased from 74.3 to $93.6 \%$ when the molar ratio $p$-cresol to cyclohexene was increased from $4: 1$ to $8: 1$.

The effect of the variation of amount of perchloric acid showed that the yield of the product increased with increase of amount of perchloric acid (Table III). Thus the yield increased from 72.1 to $93.6 \%$ on increasing the amount of catalyst from 1 to $5 \%$.

Table III: The effect of the variation of amount of perchloric acid on the reaction of $p$-cresol with cyclohexene (temperature $=140^{\circ} \mathrm{C}$, molar ratio of $p$-cresol to cyclohexene $=8: 1$, time of addition $=2 \mathrm{~h}$ and time of stirring $=1 \mathrm{~h}$ )

\begin{tabular}{lc}
\hline $\begin{array}{l}\text { Amount of catalyst, } \\
\% \text { by wt. of } p \text {-cresol }\end{array}$ & $\begin{array}{c}\text { \% Yield of 2-cyclohexyl- } \\
\text { 4-methylphenol }\end{array}$ \\
\hline 1 & 72.1 \\
2 & 85.2 \\
3 & 87.8 \\
4 & 90.3 \\
5 & 93.6 \\
\hline
\end{tabular}

Table IV shows the effect of the variation of time of reaction on the yield of the product. The yield of the product increased with the increase of time of addition (Set 1). By increasing the time of addition to a value greater than $2 \mathrm{~h}$, no significant effect on the yield was observed (Set 2). However, the yield also increased by additional stirring (Set 3 ). The best yield was obtained when the time of stirring was $2 \mathrm{~h}$. 
Table IV: The effect of the variation of reaction time on the yield of cyclohexyl $p$-cresol $\left(\right.$ temperature $=140{ }^{\circ} \mathrm{C}$, $\mathrm{molar}^{-}$ ratio of $p$-cresol to cyclohexene $=8: 1$, amount of catalyst $=5 \%$ by wt. of $p$-cresol).

(1) The effect of variation of time of addition (time of stirring $=0 \mathrm{~h}$ ).

(2) The effect of variation of time of addition (total time of reaction $=4 \mathrm{~h}$ ).

(3) The effect of variation of time of stirring (time of addition $=2 \mathrm{~h}$ ).

\begin{tabular}{ccccc}
\hline No. Time of addition $\mathrm{t}_{\mathrm{a}}, \mathrm{h}$ & Time of stirring $\mathrm{t}_{\mathrm{s}}, \mathrm{h}$ & $\begin{array}{c}\text { Total time of reaction, } \\
\mathrm{t}=\left(\mathrm{t}_{\mathrm{a}}+\mathrm{t}_{\mathrm{s}}\right), \mathrm{h}\end{array}$ & $\begin{array}{c}\text { \% Yield of 2-cyclohexyl } \\
\text {-4-methylphenol }\end{array}$ \\
\hline \multirow{3}{*}{1} & 1 & 0 & 1 & 72.4 \\
& 2 & 0 & 2 & 81.9 \\
3 & 0 & 3 & 3 & 87.4 \\
& 1 & 2 & 4 & 86.7 \\
& 2 & 1 & 4 & 95.4 \\
3 & 2 & 0 & 2 & 91.2 \\
& 2 & 1 & 3 & 81.9 \\
& 2 & 4 & 93.6 \\
\hline
\end{tabular}

Therefore, the maximum yield (95.4\%) of 2-cyclohexyl-4methylphenol was obtained under the following conditions: temperature $=140^{\circ} \mathrm{C}$, molar ratio of $p$-cresol to cyclohexene $=8: 1$, amount of perchloric acid $=5 \%$ by wt. of $p$-cresol, time of addition $=2 \mathrm{~h}$ and time of stirring $=2 \mathrm{~h}$.

The UV spectrum of 2-cyclohexyl-4-methylphenol showed strong absorption at $\lambda_{\max }=295.0 \mathrm{~nm}$ in $0.01 \mathrm{M}$ methanol solution.

The IR spectrum of 2-cyclohexyl-4-methylphenol (Fig.7) showed bands at 800-900 for the presence of 1,2,4-trisubstituted benzene ring and band at $3400 \mathrm{~cm}^{-1}$ accounted for $\mathrm{H}$ bonded $-\mathrm{OH}$. The spectrum also showed absorption bands at

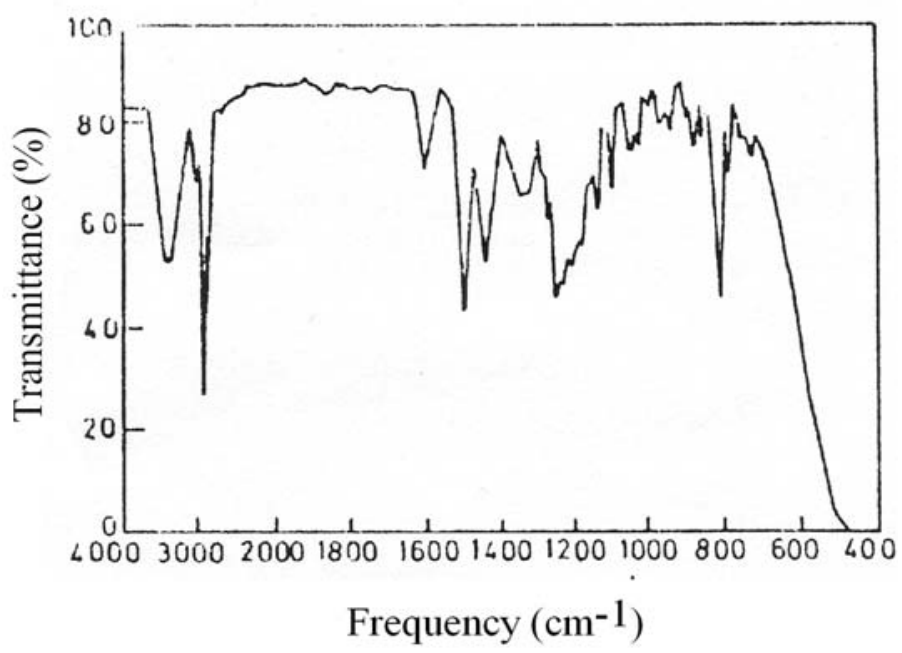

Fig. 7: IR-spectrum of 2-cyclohexyl-4-methyl phenol
$2950 \mathrm{~cm}^{-1}$ and $3000 \mathrm{~cm}^{-1}$ for saturated $\mathrm{C}-\mathrm{H}$ stretching. Band at $1600 \mathrm{~cm}^{-1}$ indicated benzene ring $\mathrm{C}-\mathrm{C}$.

Chemical shifts of the protons in the ${ }^{1} \mathrm{H}$ NMR-spectrum of 2-cyclohexyl-4-methylphenol (Fig. 8) are presented in the Table V.

Table V: ${ }^{1} \mathrm{H}$ NMR-spectrum of 2-cyclohexyl-4-methylphenol

\begin{tabular}{|c|c|c|}
\hline $\begin{array}{l}\text { Observed signals } \\
\text { of the protons }\end{array}$ & Protons & $\begin{array}{c}\text { Chemical } \\
\text { shift in } \delta \mathrm{ppm}\end{array}$ \\
\hline \multirow{5}{*}{ 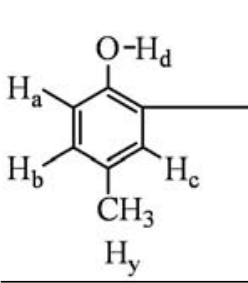 } & $a, b, c$ & $6.25-7.00$ \\
\hline & d & 6.03 \\
\hline & $\mathrm{x}$ & $2.46-3.13$ \\
\hline & $\mathrm{y}$ & $2.03-2.30$ \\
\hline & & $0.50-2.04$ \\
\hline
\end{tabular}

2-Cyclohexyl-4-methylphenol had b.p. $=270^{\circ} \mathrm{C}, \mathrm{d}_{4}{ }^{20}=$ 0.9917 and $\mathrm{n}_{\mathrm{D}}{ }^{20}=1.5218$.

\section{Alkylation of $o$-cresol}

The influence of the variation of parameters on the reaction of $o$-cresol with cyclohexene in presence of perchloric acid has been shown in Table VI. The reaction of $o$-cresol with cyclohexene under the conditions studied gave cyclohexyl $o$ cresol (cyclohexyl group substituted the aromatic ring to the ortho- and para- positions with respect to the - $\mathrm{OH}$ group). 


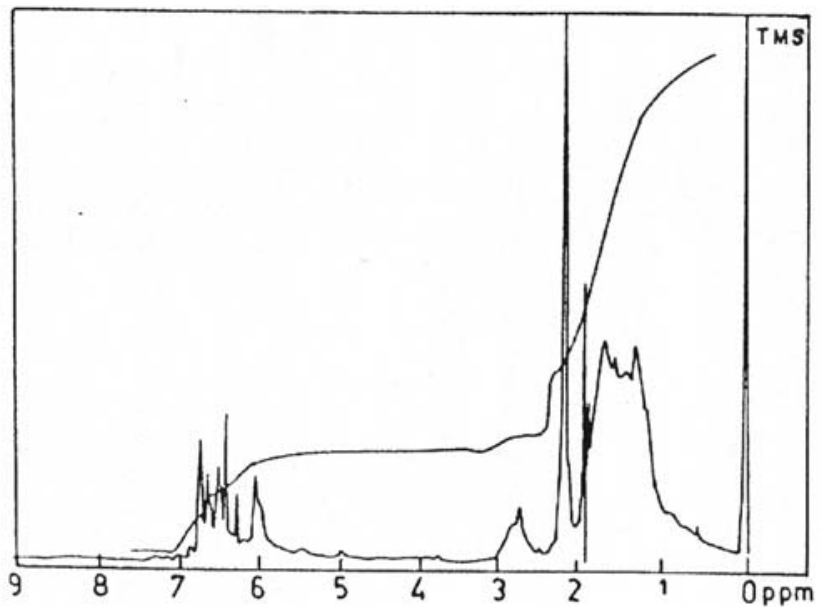

Chemical shift $(\delta)$

Fig. 8: ${ }^{1}$ H NMR-spectrum of 2-cyclohexyl-4-methyl phenol

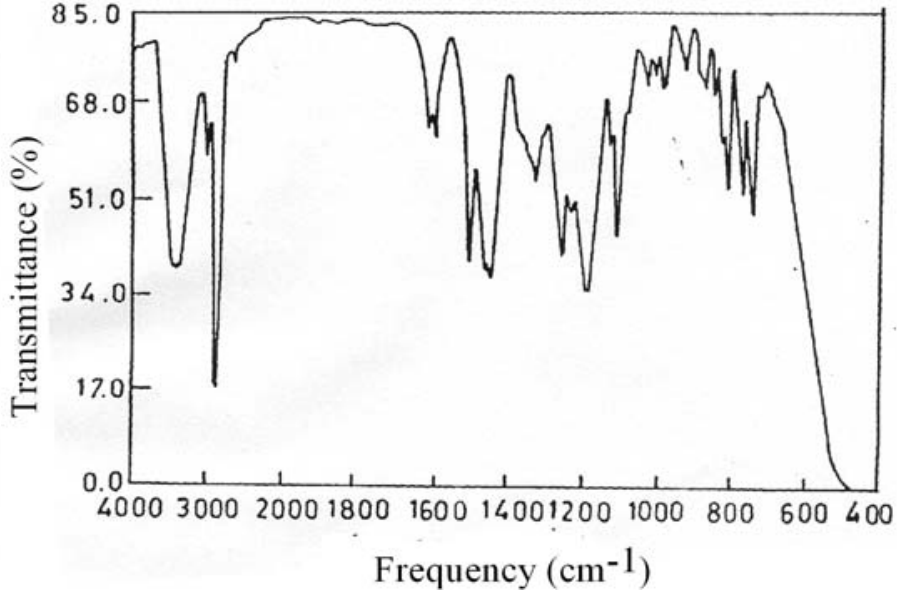

Fig. 9: IR-spectrum of cyclohexyl o-cresol

Table VI: Alkylation of $o$-cresol with cyclohexene in the presence of perchloric acid

\begin{tabular}{|c|c|c|c|c|c|c|}
\hline \multirow{2}{*}{$\begin{array}{l}\text { Expt. } \\
\text { No. }\end{array}$} & & \multicolumn{4}{|c|}{ Reaction Conditions } & \multirow{2}{*}{$\begin{array}{l}\% \text { Yield of cyclohexyl } \\
\text { o-cresol }\end{array}$} \\
\hline & $\begin{array}{l}\text { Temp, } \\
{ }^{\circ} \mathrm{C}\end{array}$ & $\begin{array}{c}\text { Molar ratio of } o- \\
\text { cresol to cyclohexene }\end{array}$ & $\begin{array}{l}\text { Amount of catalyst, } \\
\% \text { by wt. of } o \text {-cresol }\end{array}$ & $\begin{array}{c}\text { Time of } \\
\text { addition, } \mathrm{h}\end{array}$ & $\begin{array}{l}\text { Time of stir- } \\
\text { ring, } \mathrm{h}\end{array}$ & \\
\hline 1 & 60 & $4: 1$ & 1 & 2 & 1 & 41.2 \\
\hline 2 & 140 & $4: 1$ & 1 & 2 & 1 & 61.2 \\
\hline 3 & 60 & $6: 1$ & 1 & 2 & 1 & 47.8 \\
\hline 4 & 140 & $6: 1$ & 1 & 2 & 1 & 74.4 \\
\hline 5 & 60 & $4: 1$ & 5 & 2 & 1 & 44.8 \\
\hline 6 & 140 & $4: 1$ & 5 & 2 & 1 & 68.6 \\
\hline 7 & 60 & $6: 1$ & 5 & 2 & 1 & 67.4 \\
\hline 8 & 140 & $6: 1$ & 5 & 2 & 1 & 89.5 \\
\hline 9 & 140 & $6: 1$ & 5 & 2 & 2 & 91.2 \\
\hline
\end{tabular}

As can be seen from Table VI, the yield of cyclohexyl $o$ cresol increased with the increase of temperature (Expt. No. 1,$2 ; 3,4 ; 5,6$ and 7,8), molar ratio of $o$-cresol to cyclohexene (Expt. No. 1, 3; 2, 4; 5, 7 and 6, 8), amount of catalyst (Expt. No. 1, 5; 2, 6; 3, 7 and 4, 8) and reaction time (Expt. No. 8,9$)$

Thus, the reaction conditions so far studied, the best yield $91.2 \%$ of cyclohexyl $o$-cresol was obtained under the following conditions: temperature $=140^{\circ} \mathrm{C}$, molar ratio of $o$-cresol to cyclohexene $=6: 1$, amount of perchloric acid $=5 \%$ by wt. of $o$-cresol, time of addition $=2 \mathrm{~h}$ and time of stirring $=2 \mathrm{~h}$.

The UV spectrum of cyclohexyl $o$-cresol showed strong absorption at $\lambda_{\max }=296.0 \mathrm{~nm}$ in $0.01 \mathrm{M}$ petroleum ether solution.

In the IR spectrum of product (Fig. 9), absorption band at $775 \mathrm{~cm}^{-1}$ accounted for 1,2,3-trisubstituted aromatic ring, while bands near $805 \mathrm{~cm}^{-1}$ and $855 \mathrm{~cm}^{-1}$ indicated the presence of 1,2,4-trisubstituted benzene ring. Band at $3400 \mathrm{~cm}^{-1}$ indicated the presence of $-\mathrm{OH}$ group. Aromatic $\mathrm{C} \cdots \mathrm{C}$ stretch and saturated $\mathrm{C}-\mathrm{H}$ stretch were observed at $1570 \mathrm{~cm}^{-1}$ and $2850-2910 \mathrm{~cm}^{-1}$ respectively.

The ${ }^{1} \mathrm{H}$ NMR-spectrum of cyclohexyl $o$-cresol (Fig. 10) showed signal at $=6.26-7.1 \mathrm{ppm}$ for aromatic ring protons. Signals for -OH group proton, methyl group protons, all the protons on the cyclohexyl group except one on the -position relative to the aromatic ring and one proton on the $\alpha$-position were observed at $\delta=4.84 \mathrm{ppm}, \delta=2.03-2.33 \mathrm{ppm}, \delta=$ $0.94-2.03 \mathrm{ppm}$ and $\delta=2.33-3.23$ respectively.

Cyclohexyl o-cresol had b.p. $=297^{\circ} \mathrm{C}, \mathrm{d}_{4}{ }^{20}=1.0418$ and $\mathrm{n}_{\mathrm{D}}{ }^{20}=1.5459$. 


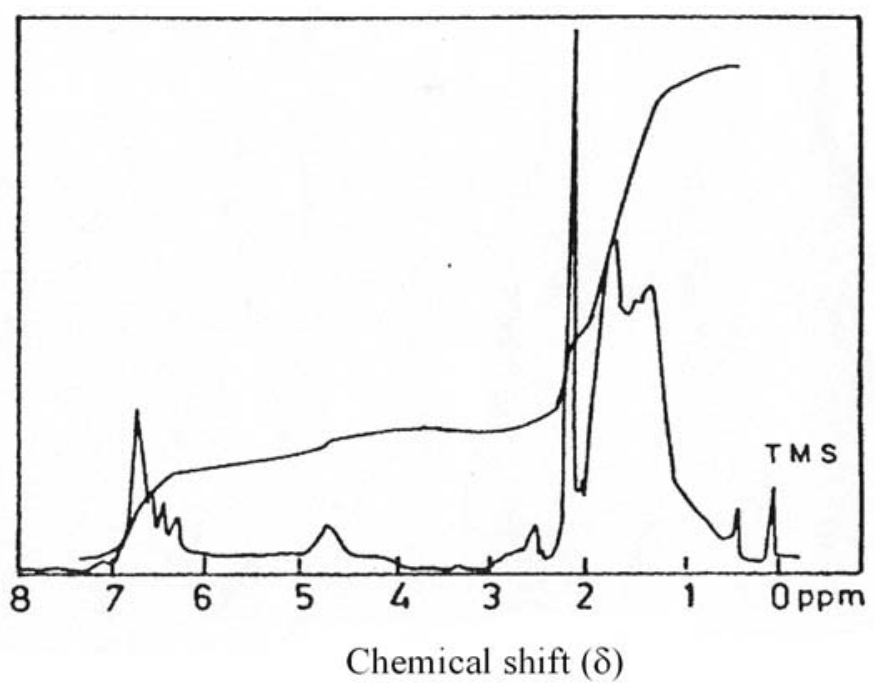

Fig. 10: ${ }^{1} \mathrm{H}$ NMR-spectrum of cyclohexyl $o$-cresol

\section{Conclusion}

The yield of alkylation of isomeric cresols with cyclohexene in presence of perchloric acid was optimized and the alkylated products were thoroughly characterized. Results of this study indicated that the effects of temperature, molar ratio of isomeric cresols to cyclohexene, amount of catalyst and time of reaction were significant. All these variables significantly affected the yield of cyclohexyl cresols. Optimum yield (97.6\% for cyclohexyl $m$-cresol; $95.4 \%$ for 2-cyclohexyl-4methylphenol and $91.2 \%$ for cyclohexyl $o$-cresol) of the products were obtained under the reaction conditions of a temperature of $140^{\circ} \mathrm{C}$; an $8-6: 1$ molar ratio of cresol to cyclohexene, a $5 \%$ by weight perchloric acid of cresol, a $2 \mathrm{~h}$ time of addition of cyclohexene and a $2 \mathrm{~h}$ time of stirring of the reaction. We hope that elaborated method of catalytic alkylation of isomeric cresols with cyclohexene in presence of perchloric acid would be a convient and an efficient method for the synthesis of alkylated phenol derivatives and results of this study would provide a convenient set of experimental conditions for the production of cyclohexyl cresols.

\section{References}

Basak PK, Saha SK, Ashaduzzaman M and Saha M 2004. Alkylation of cresols with tert-amyl alcohol. Dhaka Univ. J. Sci. 52(3): 287-292.

Chaudhuri B, Patwardhan AA and Sharma MM 1990. Alkylation of substituted phenols with olefins and separation of close-boiling phenolic substances via alkyla- tion/dealkylation. Ind. Eng. Chem. Res. 29(6): $1025-$ 1031.

Devassy BM, Shanbhag GV, Lefebvre F and Halligudi SB 2004. Alkylation of $p$-cresol with tert-butanol catalyzed by heteropoly acid supported on zirconia catalyst. J. Mol. Catal. A: Chem. 210: 125-130.

Grabowska H, Syper L and Zawadzki M 2004. Vapour phase alkylation of ortho-, meta- and para-cresols with isopropyl alcohol in the presence of sol-gel prepared alumina catalyst. Appl. Catal. A: Gen. 277(1-2): 91-97.

Grabowsk H and Wrzyszcz J 2001. C-alkylation of $m$-cresol with $n$ - and iso-propanol over iron catalyst. Res. Chem. Intermediates. 27(3): 281-285.

Kozlikovskii Ya B, Chernyaev BV, Litvin AL and Kofanova AV 1986. Reaction of $o-, m$-, and $p$-cresol with styrene in the presence of aluminum cresoxides. Zhurnal Organicheskoi Khimii. 22(7): 1469-1474.

Kozlikovskii Ya B, Koshchii VA, Butov SA and Sokolova A V 1987. Ortho alkylation of $o-, m-$, and $p$-cresols with cyclohexene in the presence of aluminum cresolates. Zhurnal Organicheskoi Khimii. 23(9): 1918-1924.

Krishnan AV, Ojha K and Pradhan NC 2002. Alkylation of phenol with tertiary butyl alcohol over zeolites. Org. Proc. Res. Dev. 6(2): 132 -137.

Lebedev NN 1984. Chemistry and Technology of Basic Organic and Petrochemical Synthesis. vols. I and II, Mir Publishers, Moscow.

Ravikovich AM 1984. Chem. Technol. Fuels Oils. 11: 68.

Sadykhov ISh, Yaskin VP, Sadykhov ShG, Mashkova TN, Gasanov MA, Prokhorova SA and Aktasheva KK 1996. Reaction of methylphenols with alkyl- and alkenylcycloalkenes. Neftekhimiya. 36(4): 362-365.

Saha M, Basak PK, Saha SK and Ashaduzzaman M 2001. Alkylation of $m$-cresol with cycloalcohols in the presence of sulfuric acid. Bangladesh J. Sci. Ind. Res. 36(14): $109-114$.

Saha M, Chowdhury S, Sarker MAB, Jolly YN and Saha D 1997. A study of alkylation of cresols with cyclooctene. Bangladesh J. Sci. Ind. Res. 32(1): 63-66. 
Saha M and Roy RK 1992. Alkylation of $m$-cresol with cyclohexanol in the presence of sulphuric acid. Bangladesh J. Sci. Ind. Res. 27(3-4): 23-29.

Sakthivel A, Badamali SK and Selvam P 2000. Selective para-t-butylation of phenol over mesoporous HAlMCM-41. Micropor. Mesopor. Mater. 39: 457-463.

Sato T, Sekiguchi G, Adschiri T and Arai K 2001. Non-catalytic and selective alkylation of phenol with propan-2ol in supercritical water. Chem. Commun. 17: 1566.

Shanmugapriya K, Palanichamy M, Balasubramanian VV and Murugesan V 2006. Vapour phase reaction of $m$ cresol and ethyl acetate over MCM-41 molecular sieves: One-pot synthesis of coumarin derivatives. Micropor. Mesopor. Mater. 95(1-3): 272-278.

Subramanian S, Mitra A, Satyanarayana CVV and Chakrabarty DK 1997. Para-selective butylation of phenol over silicoaluminophosphate molecular sieve SAPO-11 catalyst. Appl. Catal. A: Gen. 159: 229-240.

Trocsanyi Z 1975. Alkylphenol type of antioxidants, I. The alkylation of $p$ - and $m$-cresol with isobutylene. Magyar Asvanyolaj- es Foldgazkiserleti Intezet Kozlemenyei. 16: 119-129.
Velu S and Sivasankar S 1998. Alkylation of m-cresol with methanol and 2-propanol over calcined magnesiumaluminum hydrotalcites. Res. Chem. Intermediates. 24(6): 657-666.

Yadav GD and Pala R 2000. Selectivity engineering in the $\mathrm{O}$ - versus $\mathrm{C}$-alkylation of $p$-cresol with cyclohexene over sulfated zirconia. Can. J. Chem. Eng. 78(5): $917-$ 927.

Yadav GD and Pathre GS 2006. Novel meso porous solid superacids for selective C-alkylation of $m$-cresol with tert-butanol. Micropor. Mesopor.Mater. 89(1-3): 16-24.

Yadav GD, Pujari AA and Joshi AV 1999. Alkylation of $p$ cresol with methyl tert-butyl ether (MTBE) over a novel solid acid catalyst UDCaT-1. Green Chem. 1(6): 269-274.

Zhang K, Zhang H, Xu G, Xiang S, Xu D, Liu S and Li H 2001. Alkylation of phenol with tert-butyl alcohol catalyzed by large pore zeolites. Appl. Catal. A: Gen. 207: 183-190.

Manuscript received on 24 May 2011; revised on 06 September 2011; accepted on 26 September 2011. 